\title{
Sea baths as an example of sustainable architecture without an ecological footprint
}

\author{
A. B. González Avilés ${ }^{1}$, M. I. Pérez Millán ${ }^{1} \&$ C. Rubio Bellido ${ }^{2}$ \\ ${ }^{1}$ Department of Building Constructions, University of Alicante, Spain \\ ${ }^{2}$ Department of Building Science, University of Bio-Bio, Chile
}

\begin{abstract}
By the last third of the nineteenth century, many sea bath structures were raised by the Spanish Levante, but currently only San Antonio's sea bath, jutting out over the Mar Menor in Murcia, remains. The historical documentation about these seashore buildings located in Murcia and Alicante allowed us to study these architecture typologies as an approach to the design process intended to harmonize its products with nature. All the historical maps and plans, drawings and photographs convey a whole process of systematized execution with a minimum use of energy at each stage of the building process, its assembly and erection, in addition to the low maintenance and total future recycling. The adaptation of the architectural design to the coast is one of the most important aspects of these traditional constructions. This paper shows the study of different architectural, structural and constructive solutions characterized by the use of fixed and removable lightweight structures and the evolution of piling systems.

The removable feature and the simplicity of the assembly allow us to talk about an example of sustainable architecture without ecological footprints. Keywords: sea baths, bioclimatic architecture, ecological footprint, wooden architecture, removable.
\end{abstract}

\section{Introduction}

During the period when the Levante coastal resorts still existed, there was no real awareness about the concept of sustainable architecture. However, since these were port buildings and mostly temporary ones, like the ones on Alicante's Postiguet Beach, which were dismantled and reassembled year after year for the 
summer season, structures were used that nowadays we would consider as having an ecological footprint of practically zero.

The Ecological Footprint was introduced at the beginning of the $90 \mathrm{~s}$ by Mathis Wackernagel and William Rees as the total amount of ecologically productive land required to support the consumption of a given population in a sustainable way [1].

The Ecological Footprint could be defined with the following formula:

Ecological Footprint $=$ Soil, Urban Supplies + Urban Waste Soil [2].

In other words, this is an instrument that measures the influence of our way of life or our way of producing and consuming the planet.

The hypothesis of this work tries to explain an example of a sustainable architectonic system, starting from these predominantly temporary construction systems, mainly made of wood, which were assembled and dismantled year after year in the summer season, with a resource management system that is closer to $100 \%$ than to the $10 \%$ of conventional construction.

First of all, the use of wood, a material that can be recycled and reused once the working life of the building has ended, with a low environmental impact as a main material for these constructions. Secondly, thanks to the characteristics of the construction system, that is designed to be assembled and dismantled, allows the complete deconstruction of the building to recover almost all the basic materials used. In current terms, we could say this is more of a management model than an efficient construction system.

If we compare the environmental impacts of the four most commonly used systems, the traditional/conventional construction, modular concrete construction, modular steel construction and modular wood construction (in which we could consider the construction system of the resorts), we could see that the indicators for the entire life cycle where the traditional/conventional system presents a heat of $100 \%$ in the six indicators, the smallest silhouette and, therefore, the one which represents the least global impact is wood, followed by concrete, and finally steel [3].

It is true that the lack of knowledge about all the processes related to the construction of these sea bathing resort structures (the extraction and manufacturing of materials, the transportation, construction, use, maintenance, deconstruction or dismantling in this case) does not allow precisely knowing the details of each one of the phases.

\section{History}

In the 19th century, a sea bathing establishment or resort was a wooden construction, generally two stories high, located by the seashore. On the lower floor there were boxes where you could bathe in sea water. The Municipal Archives of Alicante, Murcia, and other coastal towns, as well as the Murcia Costal Demarcation, have documents from the 19th and 20th centuries that testify to the extended use of the words sea baths or resorts to refer to the 
forerunners of today's thalassotherapy centers, currently the sea baths of the 21 st Century [4].

The first document about the setting-up of a sea bathing resort on the coast of Alicante and Murcia dates back to 1834 , dealing specifically with the wooden sea baths owned by Miguel Pascual de Bonanza [5].

Bathing establishments were common along the Spanish coastline in places like La Coruña, Vigo, Palamós, Arenys de mar, Valencia, Murcia, Almeria and Malaga.

In Asturias, they appeared in 1874 [6]; in Santander at 1868, when the sons of Mayor Juan Pombo built the first bathing house in El Sardinero.

One of the first sea bathing resorts belonging to Juan Simó was constructed in 1858 at El Postiguet beach, while the port area was being renovated. Further resorts then sprung up, taking the total to twelve, with similar characteristics, all of them originally intended to be temporary (the temporary sea baths were dismantled at the end of the swimming season, to be re-installed during the next year).

The 'aerial' photograph of the beach El Postiguet taken from Alicante castle during the summer season provides evidence of this temporary situation when it is compared to the photograph taken in winter, when such structures were removed (Figure 1).

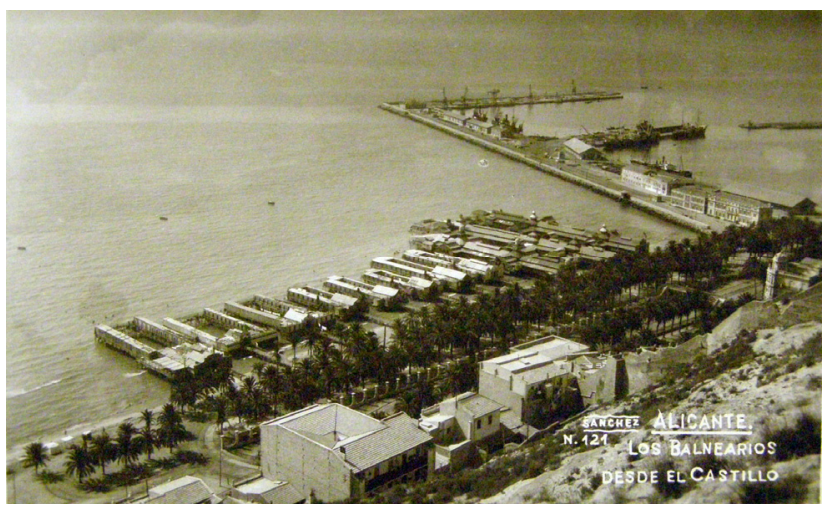

Figure 1: The 'aerial' photograph of the beach El Postiguet taken from Alicante castle during the summer. It shows 4 fixed baths and 7 temporal baths.

\section{Case study: implementation of a sea bathing resort}

\subsection{Foundation}

One of the main characteristics of the sea bathing resorts was building a construction whose structure is based on "feet" nailed to the sea bed, creating a platform elevated above sea level on which the building is erected. These "feet" had a two-fold role of lifting the platform above the water and providing a safe 
foundation, looking for resistant layers under the lake bed. It is, therefore, a foundation made through piling.

A piling foundation is defined by a group of piles nailed on the ground and spread either directly under the application point of the loads, or consolidating the entire area. It is a foundation for loose or soft soil, and especially those that become flooded or that have an elevated and constant level of moisture. The pilots can resist friction or reaction on the tips. The first ones are the most current and their resistance is based on the adherence and resistance to their driving. Those which reach firm ground transmit the load they receive at the top, avoiding bending from rubbing with the ground.

The first pilots used as foundations in the sea bathing resorts at the end of the 19th century, were more or less straight, mainly pine and eucalyptus wooden $\operatorname{logs}$, that were 12 to $15 \mathrm{~cm}$ in diameter. They used to be distributed in screens with a separation of $2 \mathrm{~m}$, which establishes a support relationship of $0.0177 \mathrm{~m}^{2} / 4 \mathrm{~m}^{2}$ or whatever is the same for each $100 \mathrm{~m}^{2}$ of construction so the contact with the ground does not exceed $0.5 \mathrm{~m}^{2}$. Their tronconic shape was ideal for driving them, with the tip placed on the finest part, as in this way it penetrated better and its rubbing with the earth was favored. The tip was flame hardened, reinforced with metal tips or protected with forged or smelted piles, considerably improving their driving. This was done using drop hammers or pile drivers, letting these repeatedly fall with thrust on the top of the pile. The top was reinforced with a metallic ring to keep the fibers of the log from opening up with the impacts, and from wigging being formed, which softened the blows.

The wooden piles driven into the sea bed had the issue of being too sensitive to storms and collisions of vessels, along with crustaceans, their main enemies, attaching themselves. For this reason, years later, the logs started receiving protection against erosive agents which went around the pile or they were substituted by metal piles. In the case of the Alianza sea resort in Alicante, with fifty-four $0.2 \mathrm{~m}$ diameter metal piles $\left(1.7 \mathrm{~m}^{2}\right.$ of support), a $900 \mathrm{~m}^{2}$ platform was supported.

When the depth of the waters required that a large part of the piles was uncovered and with a pronounced slenderness, horizontal bracing was done using Saint Andrew crosses based on wooden boards nailed to the piles (Figure 2).

\subsection{Platform's horizontal framework}

One of the main roles of the piles was lifting the horizontal platforms of the sea bathing resorts above the water. For this, the top of the wooden logs was cut at the same level to guarantee the horizontality of the boarding for the ones working as support.

Sawn wooden transversal boards, called cleats or marranos, were placed on the piles to tie their tops (Figure 3). To secure the joint between the board and the pilot, mortising was done on its top. The joint was made by nailing the two pieces, using wooden wedges to level out the bolsters. It was also possible to place this board on the stake's top without using mortising, but this solution, 


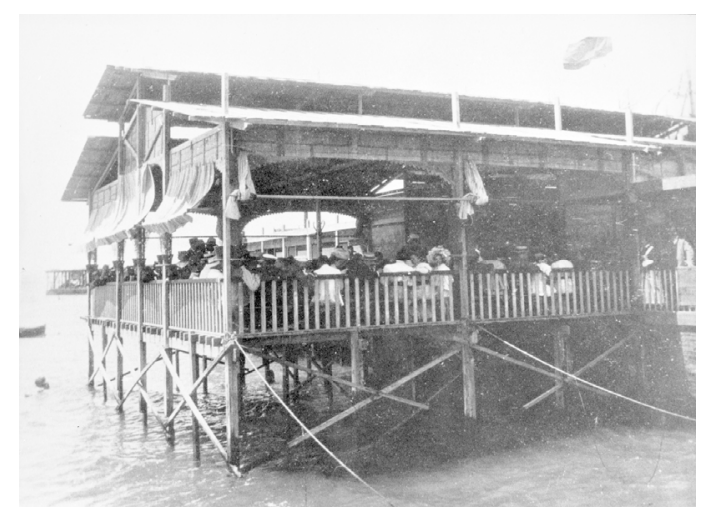

Figure 2: Horizontal bracing using Saint Andrew crosses in the Torrevieja sea bathing resort. Photo collection - image from disc 3-7 and 3.3.

seen in the projects' original plans, is not seen in sea bathing resorts which still remain standing in the Mar Menor. On occasions, the cleats were connected to each other perpendicularly on the same plane using boards, securing the bracing of the platform's final structure.

Appropriately nailed boards or bolsters, running longitudinally, are placed perpendicularly on the cleats. The bolsters are placed not only on the center lines of the piles, but also between them, forming a grid so that the rafters receive the boarding which creates the platform's transitable surface. At the same time, these bear the loads that the structure carrying the bathing huts transmits to them.

In more complex structures, like those for larger public sea bathing resorts, the placing of bolsters varied in regards to those used in family bathing resorts where, given their scarce structural requirements, these were placed uniformly on the bolsters.

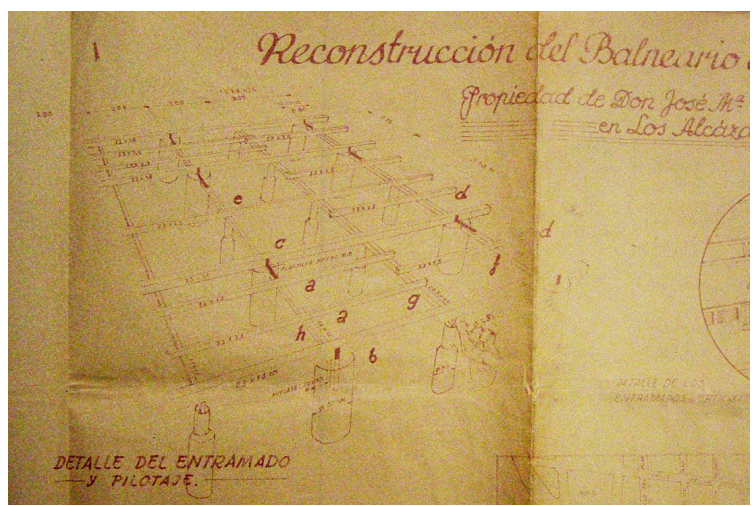

Figure 3: Layout of the cleats or marranos and the bolsters. Costas Murcia Archives. File C 302 MY San Antonio, Los Alcazares sea bathing resort. 


\subsection{Vertical supports}

Traditionally, the supports used for the structural setup of the huts and other constructions placed on the platform were simple in nature, formed by a single rectangular or square section. This was logically the largest section in the large social bathing resorts, where the stresses required structures with a greater resistance.

The supports were generally supported on the bolsters, either directly or by using a horizontal nailed joint when the supporting shaft did not match their shaft, using wooden pads when the separation between them so required. To get the support on the bolsters, mortising was used on the pieces of the platform's boarding that were affected. This type of joint was also used to fix the railing posts that existed to avoid falling into the water.

The porticos were horizontally braced both with the beams that were placed on the pillars and with brackets placed at an average height, which also served as support for nailing the boards that formed the external finish of the installations.

\subsection{Beams}

The horizontal beams, generally made of sawn wood, were placed on the tops of the pillars (Figure 4). Their main role in large publicly used resorts, like the one in San Antonio, was to work as a support or sleeper and to receive the loads of the supports and cradles which held the tiled covers that were typical of these constructions.

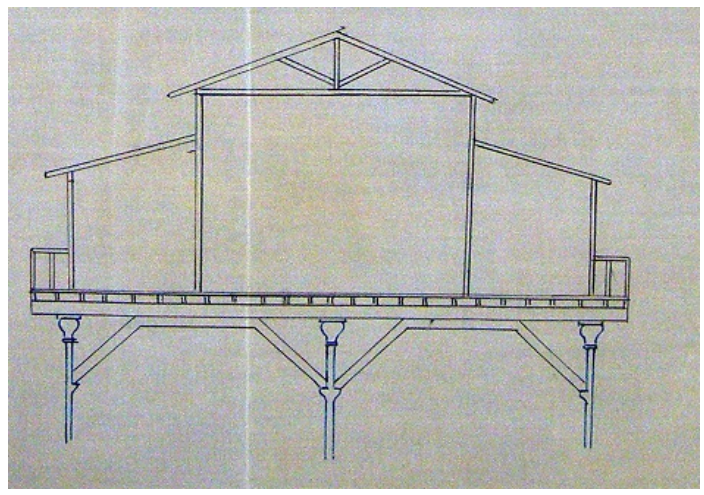

Figure 4: Plan of the Confianza Sea Bathing Resort in El Postiguet. Alicante 1897. Alicante Provincial Archives. OP-G 180.

\subsection{Structure of the cover}

Most of the sea resorts had inclined covers, with single or double pitch roofs. In the large social type resorts which are still standing today, one can see different structural systems to resolve the problem that covering using large lights between supports implied. To find a solution for this problem, covers with trusses or supports were used (Figure 5). In these structures, the qualities of the wood were used to their fullest, to have larger lights. 


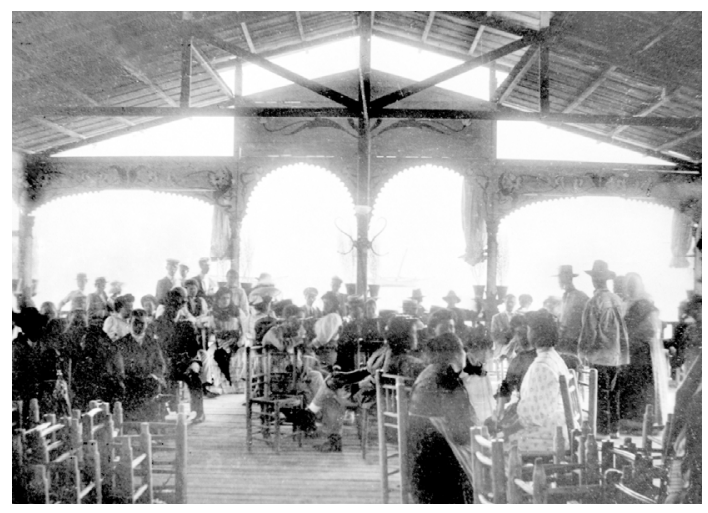

Figure 5: Cradle trusses and joggle-posts inside the bathing resort in Torrevieja. Photo Collection, image on disc 3-7 and 3-3.

The covers of supports, typically made with a double pitch roof, are built with very resistant elements (trusses), suitably placed on the points to receive the loads of the tethers that only bear flexion stresses from the weight of the cover and wind loads. To bear the cover in its central wing, with a double pitch roof, cradle and joggle-post supports were used, but with the variant of having the strut elevated, dividing the cradle's lights. The joggle-post is the piece of the intermediate prop that provides rigidity to the structure and limits the sag of the cradles.

\subsection{Partitions and gaps}

In larger sea bathing resorts, where the huts had everything inside the same volume (as in the accommodation resorts), the internal divisions were done in the same way as the public use sea bathing resorts and the communal bathing rooms. As it has been shown above, the central space of this type of structure was traditionally permeable and was destined for walking to the structure's end platform or, if its size allowed, to the multiuse room. Therefore, the partitions were placed in the spaces existing in the side wings, taking advantage of the light between their supports.

To establish the division, a substructure of wooden brackets was built between the supports on the plane perpendicular to the wing's axis. If the walls entirely enclosed the space to make the huts independent from each other, the cover's cradle was used as an upper bracket of the substructure. Wooden boarding of just of few centimeters thick was nailed to this framework which made the effective division.

The gaps that exist in the bathing resort's walls, also needed structures incorporated to the general structure. In the case of the internal doors, lengthwise brackets were placed as a sub-frame, anchored on the top part on the supporting beam of the cover's cradles and supported on the bolsters of the platform on the lower part of this. Normally, the doors were placed next to the pillars, only 
needing a bracket to complete the frame (Figure 6). In this way, not only did they act as a supporting element for the door, but they also alleviated the weight that the supports received from the beams.

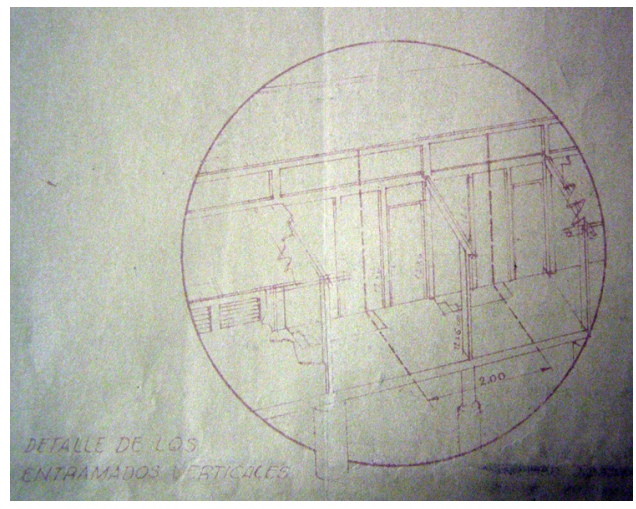

Figure 6: Substructure of brackets to make the divisions of the huts. Costas Murcia Archives, File C 302 MU.

The façade walls followed the same setup for their enclosure, also using brackets as a supporting point to nail the finish layer which, as will be analyzed in the next paragraph, used to also be built in the same way as the partitions: with wooden boarding although with thicker pieces.

The hollow of the windows adopted a similar method for their setup. Here, two bolsters were placed horizontally, joined at their ends to the adjacent pillars. The separation between both provided the height of the window, while the width was formed by two brackets placed perpendicularly to these and centrally placed between the pillars.

The sum of all the main supporting system's structural elements, those of the covers and those belonging to the substructures supporting the partitions and hollows, as a result, offered authentic wooden frameworks perfectly braced in both directions with great effectiveness and control.

\section{Ecological footprint}

After the detailed description of the sea bathing resort construction process, we have been able to understand the rationalism and the efficiency of their construction in wood. Now, we will see their ecological footprint. Several authors have explained the concept of ecological footprint in their research and on what factors it depends.

If we focus on the study done by Solís-Guzmán et al. [7], where they evaluate the ecological footprint of the building sector of the Andalusian community in residential use, we understand that the affection area must fundamentally cover 3 phases: The architectonic construction, maintenance and use phases and, finally, the demolition-deconstruction phase. Thus for example, it collects that 
the impact sources are derived from direct consumption (they cause direct use of resources onsite through the energy or water expense), indirect consumption (labor, food, use of fuel for moving objects and the consumption of construction materials), generation of waste from the construction and demolition (CDW), and, finally, the built surface area which involves the consumption of land and therefore a footprint on this.

The procedure studied by Solís-Guzmán et al. has been followed for the study of sea bathing resort construction, adapting it to this type of quite particular buildings.

\section{Strategies}

To calculate the ecological footprint of this type of buildings, the parameters to determine the following footprints have been taken into account:

- $\quad$ Built surface footprint;

- Construction materials footprint;

- Energy footprint.

The waste and mobility footprint parameter has not been studied, as this is a building where everything can be dismantled, stored on the same beach and reused every summer.

\subsection{Built surface footprint}

Since this is a surface area reclaimed from the sea, unproductive from an agrarian point of view, when facing other constructions built on production land, it can be considered in this case that the footprint will be zero, as it does not affect the surface it is on. The equivalence factor corresponding to the land (forestry or crops) will not apply either. Neither vegetation nor existing trees are eliminated for its construction, therefore, the footprint cannot be analyzed as in other constructions in light of the amount of $\mathrm{CO}_{2}$ that it can absorb.

\subsection{Construction materials footprint}

The consumption of construction materials presents a series of particular characteristics that complicate the calculation of its footprint, as it depends on energy consumption from manufacturing, transportation and its setting up.

The material used in these sea bathing resort constructions was wood. According to the guide on sustainable building, energy quality and the environment in building, from the Development Ministry, the specific energy incorporated from the wood is $3 \mathrm{MJ} / \mathrm{kg}$. Wooden structures are generally found to be preferable since they are less energy and carbon intensive when compared to non-wood structures [8].

The construction of wooden sea bathing resources has a two-fold positive effect in the reduction of greenhouse gases, on one hand, wood stores a high amount of carbon which, in this way, is not emitted into the atmosphere. On the other, if we use wood from sustainably managed forests, the felling of a tree will mean the planting of new young tree which, through the photosynthesis process, 
will absorb more $\mathrm{CO}_{2}$ from the atmosphere than a fully-grown tree. The theory that building with wood has a beneficial negative $\mathrm{CO}_{2}$ footprint for the environment is based on these two rationale.

Wood-framed construction requires less energy, and emits less $\mathrm{CO}_{2}$ into the atmosphere, than concrete-framed construction. The lifecycle emission difference between the wood and concrete-framed buildings ranges from 30 to $130 \mathrm{~kg} \mathrm{C}$ per $\mathrm{m}^{2}$ of floor area [9].

\subsection{Energy footprint}

To predict the energy consumption produced in the construction of one of the sea bathing resorts, this has been estimated based on the data which the formulas that the State has set since the 70 s provide.

For example, if we take as reference the polynomic formulas that the State published in 1970, when some of the sea bathing resorts were still standing, we can see that no reference whatsoever is made to this type of building. There was no formula that included port facilities with wooden structures.

If we focus on paragraph 3 Port Works of the current RD. 1359/2011 from October 7th 2011, which approves the relation of basic materials and the general price revision standard formulas of works contracts, the formula that best fits the type of construction being studied is 632 , Construction of wooden maritime promenades.

FORMULA 632. Construction of wooden maritime promenades

$$
\begin{gathered}
\mathrm{Kt}=0.07 \mathrm{Ct} / \mathrm{C} 0+0.03 \mathrm{Et} / \mathrm{E} 0+0.04 \mathrm{Ft} / \mathrm{F} 0+0.19 \mathrm{Mt} / \mathrm{M} 0 \\
+0.08 \mathrm{Rt} / \mathrm{r} 0+0.03 \mathrm{St} / \mathrm{S} 0+0.56
\end{gathered}
$$

The coefficients represent the total for one over the total amount of each type of work. Said amount is considered without VAT, once the industrial profit and general expenses are discounted. $56 \%$ would be the indirect costs.

The basic materials included in this formula are shown in table 1:

Table 1: $\quad$ Table of coefficients of the formula 632 from RD. 1359/2011.

\begin{tabular}{|l|l|l|l|l|l|l|l|}
\hline $\mathrm{N}^{\mathrm{o}}$ & $\mathrm{C}$ & $\mathrm{E}$ & $\mathrm{F}$ & $\mathrm{M}$ & $\mathrm{R}$ & $\mathrm{S}$ & $\mathrm{CI}$ \\
\hline 632 & 0.07 & 0.03 & 0.04 & 0.19 & 0.08 & 0.03 & 0.56 \\
\hline
\end{tabular}

Table 2: $\quad$ Table of materials' symbology from RD. 1359/2011.

\begin{tabular}{|l|l|l|l|}
\hline Symbol & Material & Symbol & Material \\
\hline A & Aluminum & P & Plastic products \\
\hline B & Bituminous materials & Q & Chemical products \\
\hline C & Cement & R & Aggregate and rocks \\
\hline E & Energy. & S & Iron and steel materials \\
\hline F & Lamps and lights & T & Electronic materials \\
\hline L & Ceramic materials & U & Copper \\
\hline M & Wood & V & Glass \\
\hline
\end{tabular}


The energy consumption of this type of sea bathing resort construction would be $3 \%$ against concrete or steel constructions where this would never drop below $9 \%$.

\section{Conclusions}

The sea bathing resorts meet a hygiene demand of the 19th century in that the modesty and fear of bathing contrasted with the medicinal benefits of bathing. Its effective and low cost architecture allowed someone to get into the water to overcome the unhealthiness of the coastline, allowing changing clothing and climbing down a private staircase to bathe without needing to know how to swim and without being seen. As time went by, this type of architecture disappeared with the regeneration of the beaches and the change in culture towards bathing. Almost two centuries later we can guarantee the very low ecological footprint index that this type of constructions had on our coasts. The material they were made with and that they could be dismantled supports this theory yet further. Thanks to the piloting, only $0.5 \%$ of the surface of the sea bathing resort's platform was needed, transferring the load to the sand; the rest of the weight was transmitted by friction.

Current architecture, like the Kastrup Bathing Platform in Copenhagen, adapted to the new leisure and bathing needs, but with similar construction processes, serve as an example of the adaptation of this sea bathing resort typology and the low environmental impact that can be achieved. Kastrup Søbad won both a bronze medal in the Olympic Committee's competition for the best sport and leisure building and a prize for the best handicap conditions, which was awarded in association with the International Paralympic Committee (IPC).

\section{References}

[1] Wackernagel M., Rees W. E. Our Ecological Footprint: Reducing Human Impact on the Earth. New Society, Gabriola Island, B.C., Canada, 1996.

[2] Cárdenas Priego, Josué Ramón. Buenos ejemplos en la práctica de la construcción sostenible en el mundo contemporáneo, en Procesos Urbanos Revista de Divulgación Científica, vol. 1, pp. 113-120, 2014.

[3] G. Wadel, J. Avellaneda, A. Cuchí. La sostenibilidad en la arquitectura industrializada: cerrando el ciclo de los materiales, en Informes de la Construcción, Vol. 67, 517, pp. 37-51, 2010.

[4] González Avilés, A. B. Perez Millán, M. I. López López, J. M. Bath construction at the Spanish Mediterranean seaside: maritime heritage for the coast environment, en WIT Transactions on The Built Environment. 2015, 148: 125-134. doi:10.2495/CC150111.

[5] Ramos Pérez, V. Historia de la provincia de Alicante y su capital, ed. Diputación Provincial, Alicante, 1971.

[6] Roza Candás, M. Los balnearios maritimos en Asturias (1848-1935), ed. Fundación Alvargonzález, Gijón, p. 81, 1995. 
[7] Solís-Guzmán, J. Marrero Meléndez, M. Montes-Delgado, M.V. Ramírezde-Arellano, A. A Spanish model for quantification and management of construction waste. Waste management, ISSN-e 0956-053X, No.9, pp. 2542-2548, 2009.

[8] A.H. Buchanan, B.G. Honey; Energy and carbon-dioxide implications of building construction. Energy Buildings, 20, pp. 205-217, 1994.

[9] L. Gustavsson, K. Pingoud, R. Sathre; $\mathrm{CO}_{2}$ balance of wood substitution: comparing concrete- and wood-framed buildings. Mitigation and Adaptation Strategies for Global Change, 11, pp. 667-691, 2006. 